\section{SOSIALISASI PENTINGNYA CUSTOMER RELATIONSHIP MANAGEMENT (CRM) DALAM UPAYA MENINGKATKAN RETENSI PELANGGAN PADA USAHA MIKRO KECIL DAN MENENGAH (UMKM) DI CILEGON}

\author{
Vidila Rosalina ${ }^{*}$, Abdul Malik2 \\ dan Erma Perwitasari3
}

\author{
1) Teknik Informatika, Universitas \\ Serang Raya \\ 2) Akuntansi, Universitas Serang Raya \\ 3) Sistem Informasi, Universitas \\ Serang Raya
}

\section{Article history \\ Received \\ : 16-10-2017 \\ Revised \\ : 09-11-2017 \\ Accepted \\ : 22-10-2017}

*Corresponding author

Vidila Rosalina

Email :

vidila.suhendarsah@gmail.com

\begin{abstract}
Abstraksi
Usaha Mikro Kecil dan Menengah (UMKM) di wilayah Banten sebagian besar masih dikelola dengan metode konvensional, sentuhan teknologi informasi belum optimal. Salah satu pendekatan bisnis modern adalah dengan memperhatikan faktor pelanggan, bukan saja sebelum transaksi, tapi tidak kalah penting adalah setelah transaksi. Sistem Teknologi Informasi yang digunakan untuk mengelola pelanggan dengan tujuan untuk meningkatkan retensi pelanggan ini disebut dengan Customer Relationship Management (CRM). Perangkat lunak CRM yang sekarang ada lebih berorientasi ke perusahaan besar yang sudah mapan, sehingga akan menimbulkan beberapa ketidaksesuaian ketika diterapkan dalam UMKM. Pengabdian ini mencoba melakukan sosialisasi pentingnya CRM pada UMKM dalam meningkatkan retensi pelanggan UMKM. Penerapan CRM ini akan membantu UMKM dalam pengelolaan hubungan dengan pelanggan sehingga dapat meningkatkan daya saingnya dengan perusahaan lain dalam mempertahankan bisnis yang dijalankan dan sebagai sarana untuk memperoleh pasar baru yang lebih luas. Pendekatan yang digunakan adalah menggunakan model 'lokalisasi' melalui observasi yang dilakukan pada usaha UMKM yang tergabung pada Himpunan Pengusaha Mikro Kecil dan Menengah Indonesia (HIPMIKINDO) Cilegon. Hasil pengabdian ini diharapkan mampu memberikan gambaran tentang pentingnya CRM pada UMKM di wilayah Banten.
\end{abstract}

Keywords: CRM, HIPMIKINDO, Retensi Pelanggan, UMKM

\begin{abstract}
- dalam bahasa inggris
Micro Small and Medium Enterprises (SMEs) in Banten region is still largely managed by conventional methods, the touch of information technology has not been optimal. One of the modern business approaches is to pay attention to the customer factor, not just before the transaction, but no less important is after the transaction. The Information Technology system used to manage customers with the aim of increasing customer retention is called Customer Relationship Management (CRM). The existing CRM software is more oriented to large established companies, so it will cause some discrepancies when applied to MSMEs. This dedication tries to socialize the importance of CRM to UMKM in increasing the retention of SME customers. Implementation of this CRM will help SMEs in the management of customer relationships so as to improve its competitiveness with other companies in maintaining the business run and as a means to gain a new market wider. The approach used is using the model of 'localization' through observations made on SMEs business incorporated in the Association of Small and Medium Enterprises Indonesia (HIPMIKINDO) Cilegon. The results of this dedication is expected to provide an overview of the importance of CRM to MSMEs in the region of Banten.
\end{abstract}

Keywords: CRM, HIPMIKINDO, Customer Retention, UMKM

\section{PENDAHULUAN}

\section{Analisis Situasi}

Pengertian UMKM dijelaskan dalam undangundang nomor 20 tahun 2008. Pengertiaan UMKM dibagi menjadi tiga, yaitu usaha mikro, usaha kecil, dan usaha menengah. Usaha Mikro adalah usaha produktif milik orang perorangan dan/atau badan usaha perorangan yang memenuhi kriteria Usaha
Mikro sebagaimana diatur dalam Undang-Undang ini. Usaha Kecil adalah usaha ekonomi produktif yang berdiri sendiri, yang dilakukan oleh orang perorangan atau badan usaha yang bukan merupakan anak perusahaan atau bukan cabang perusahaan yang dimiliki, dikuasai, atau menjadi bagian baik langsung maupun tidak langsung dari usaha menengah atau usaha besar yang 
memenuhi kriteria Usaha Kecil sebagaimana dimaksud dalam Undang-Undang ini. Usaha Menengah adalah usaha ekonomi produktif yang berdiri sendiri, yang dilakukan oleh orang perseorangan atau badan usaha yang bukan merupakan anak perusahaan atau cabang perusahaan yang dimiliki, dikuasai, atau menjadi bagian baik langsung maupun tidak langsung dengan Usaha Kecil atau usaha besar dengan jumlah kekayaan bersih atau hasil penjualan tahunan sebagaimana diatur dalam UndangUndang ini.

UMKM merupakan salah satu sektor penggerak ekonomi Indonesia yang mampu bertahan dalam menghadapi ketatnya persaingan bisnis global seperti saat ini. Jumlah pekerja disektor UMKM awal tahun 2012 hampir mencapai 80 juta orang, hal ini memerlukan perhatian lebih untuk mendorong pengelola UMKM dalam meningkatkan pemberdayaan usahanya. Ada beberapa faktor yang mempengaruhi kinerja UMKM dalam mempertahankan bisnisnya, diantaranya pembiayaan, SDM, pangsa pasar, iklim usaha, sarana dan prasarana pendukung, dan akses informsi (Rifa'i, 2013).

Ada beberapa kendala yang bisa menghambat kinerja UMKM dalam mempertahankan bisnisnya. Peni Sawitri, dkk (2012) mengatakan bahwa kendala yang sering dihadapi UMKM kesulitan dalam memasarkan produk-produknya dan mempertahankan pasar yang sudah ada, serta kendala inovasi dan manajemen keuangan yang belum optimal menyebabkan pelaku usaha UMKM tidak dapat bertahan lama. Untuk dapat bertahan dalam mempertahankan bisnisnya, UMKM dituntut untuk dapat mulai menerapkan berbagai macam strategi dalam upaya pengembangan usahanya. Setiap pelaku Usaha UMKM tidak hanya dituntut untuk bisa menciptakan produk-produk unik namun juga harus memiliki kemampuan dalam hal memasarkan produk. Tanpa didukung strategi pemasaran yang baik, dapat dipastikan bahwa pemberdayaan UMKM tidak dapat berkembang pesat.

Pemasaran berkembang dengan pesat dan memahami perilaku konsumen menjadi salah satu strategi dalam keberhasilan memasarkan produk. Kendala yang sering dihadapi sebagian besar Usaha Mikro Kecil Dan Menengah (UMKM) adalah kesulitan memasarkan produk-produknya dan mempertahankan pasar yang sudah ada di samping beberapa kendala lain seperti inovasi tidak optimal, keuangan rumah tangga bercampur dengan keuangan industri dan manajemen tradisional. Pemahaman dan mempertahankan pelanggan menjadi salah satu strategi dalam keberhasilan perusahaan. Hal ini sering menjadi kendala utama pada UMKM di tengah persaingan yang semakin ketat. UMKM perlu menjaga hubungan baik dengan pelanggan dan meningkatkan loyalitasnya melalui pengetahuan dan pemenuhan kebutuhan pelanggan dengan cepat dan tepat. Customer Relationship Management (CRM) sebagai aplikasi teknologi informasi akan mampu mengatasi masalah tersebut karena CRM bertujuan mengelola hubungan dengan pelanggan. CRM dapat membantu UMKM mengembangkan produk baru berdasarkan pengetahuan yang lengkap tentang keinginan pelanggan, dinamika pasar dan pesaing. Dengan demikian dalam rangka UMKM mendapatkan pengertian yang lebih baik tentang pelanggan mereka dan kebutuhan mereka dilakukan kombinasi gudang data, bank data dan meja bantu atau pusat panggilan (call center).

Penelitian ini dilakukan untuk mengembangkan perangkat lunak CRM pada usaha mikro kecil dan menengah. Masih sedikit UMKM yang telah menerapkan CRM ini walaupun sudah banyak UMKM menyadari pemanfaatan sistem informasi menjadi suatu keharusan yang tidak dapat dihindari oleh setiap usaha yang ingin menempatkan dirinya pada posisi paling depan dalam suatu industri. Danardatu (2003) Aplikasi CRM saat ini sudah banyak beredar di pasaran, kebanyakan dibuat oleh perusahaan Amerika dan Eropa yang telah lebih dulu mengimplementasikan CRM di perusahaan mereka. AMR Research melaporkan beberapa penyedia software CRM seperti Siebel Systems, Microsoft, Clarify (Nortel Networks), PeopleSoft dan Oracle sebagai pemimpin pasar.

Sementara itu perusahaan-perusahaan penyedia jasa profesional CRM sebagai pemimpin pasar misalnya Accenture, Art Technology Group, Cambridge Technology Partners, CSC, Deloitte Consulting, EDS, eLoyalty, Cap Gemini Ernst \& Young, IBM Global Services, KPMG Consulting dan Price Waterhouse Coopers. Hal ini menunjukkan bahwa penyedia software CRM sebagian besar adalah perusahaan-perusahaan asing yang mungkin membuat UMKM enggan memanfaatkan aplikasi CRM ke dalam usaha bisnisnya, karena mahalnya aplikasi tersebut dan vendor asing masih kurang memahami persiapan proses bisnis usaha kecil dan menengah yang unik. Hal inilah yang memotivasi pengabdian ini dilakukan untuk membantu UMKM dalam menerapkan CRM. Dengan demikian rumusan masalah dalam pengabdian ini adalah "Bagaimanakah kesiapan Usaha Mikro Kecil dan Menengah (UMKM) di Cilegon dalam menerapkan Customer Relationship 
Management (CRM) dalam rangka meningkatkan retensi pelanggan dan membangun pemasaran skala global pada UMKM di wilayah Banten?".

Berdasarkan survey yang dilakukan pada 30 Usaha Mikro Kecil Dan Menengah (UMKM) yang tergabung pada Himpunan Pengusaha Mikro Kecil dan Menengah Indonesia (HIPMIKINDO) Cilegon , pada umumnya para pelaku UMKM masih memiliki tingkat pengetahuan Customer Relationship Management (CRM) yang rendah dan masih belum memanfaatkan Customer Relationship Management (CRM).

Tabel 1. Data Responden Tingkat Pemanfaatan CRM

\begin{tabular}{llc}
\hline No & Tingkat Pemanfaatan & CRM \\
\hline \hline 1 & Tidak Pernah & 30 \\
\hline 2 & Kadang-kadang & 0 \\
\hline 3 & Pernah & 0 \\
\hline 4 & Sering & 0 \\
\hline \hline
\end{tabular}

Dan secara umum para pelaku UMKM belum memanfaatkan TIK dalam kegiatan proses bisnisnya seperti yang terlihat pada Tabel 2.

Tabel 2. Data Responden Tingkat Pemanfaatan TIK

\begin{tabular}{llc}
\hline No & Tingkat Pemanfaatan & TIK \\
\hline \hline 1 & Tidak Pernah & 22 \\
\hline 2 & Kadang-kadang & 5 \\
\hline 3 & Pernah & 2 \\
\hline 4 & Sering & 1 \\
\hline \hline
\end{tabular}

Dan secara umum para pelaku UMKM sebagian besar memanfaatkan smartphone dalam kegiatan proses bisnisnya seperti yang terlihat pada Tabel 3 .

Tabel 3. Data Responden Tingkat Pemanfaatan Smartphone

\begin{tabular}{llc}
\hline No & Tingkat Pemanfaatan & Smartphone \\
\hline \hline 1 & Tidak Pernah & 0 \\
\hline 2 & Kadang-kadang & 1 \\
\hline 3 & Pernah & 0 \\
\hline 4 & Sering & 29 \\
\hline \hline
\end{tabular}

\section{Permasalahan UMKM}

UMKM (Usaha Mikro Kecil dan Menengah) di Indonesia atau di Banten khususnya memiliki beberapa kendala dalam mengelola hubungan dengan pelanggan-pelanggannya, sehingga kualitas pelayanan menjadi kurang optimal yang mengakibatkan berkurangnya retensi pelanggan. Beberapa kendala tersebut antara lain :

a. Kompetensi pelaku UMKM yang relatif rendah dan kurang memahami pentingnya pemanfaatan CRM. b. Masih terbatasnya pemanfaatan TIK dalam kegiatan proses bisnis UMKM.

c. Para pelaku UMKM belum memiliki database pelanggannya.

Kegiatan pengabdian masyarakat sosialisasi pentingnya Customer Relationship Management (CRM) dalam upaya meningkatkan retensi pelanggan pada Usaha Mikro Kecil Dan Menengah (UMKM) di Cilegon diharapkan atau dihasilkan dari kegiatan ini adalah:

a. Para pelaku UMKM di wilayah Cilegon memahami pentingnya pemanfaatan CRM dalam kegiatan proses bisnisnya dalam upaya meningkatkan retensi pelanggannya.

b. Para pelaku UMKM di wilayah Cilegon memahami pentingnya pemanfaatan CRM dalam kegiatan proses bisnisnya dalam upaya melakukan pemasaran global.

\section{METODE PELAKSANAAN \\ Metode Penyelesaian Masalah}

Untuk mengantisipasi permasalahan yang dihadapi oleh UMKM (Usaha Mikro Kecil dan Menengah) menggunakan dua metode pendekatan, yaitu:

Metode pertama, menggunakan metode pendekatan Kaji Tindak (Action Research) .Kleiman et al. (2001) mengemukakan bahwa metode kaji tindak merupakan jenis program aksi yang dapat menghasilkan pengetahuan baru dalam rangka pemecahan masalah atau perbaikan terhadap masalah dalam kehidupan praktis .Ada dua tujuan utama dari metode ini yaitu berupa penemuan metode baru dalam pemecahan masalah secara praktis oleh tim pelaksana program, sedangkan pemilik masalah mendapatkan metode yang lebih efisien dalam pemecahan masalah secara praktis di lapangan (Burns, 1994). Dalam kaji tindak partisipatif, kerja sama antara tim pengusul dengan "pemilik masalah" (problem owner) merupakan hal penting untuk diterapkan. Ketergantungan saling menguntungkan antara tim dan pemangku masalah terletak pada pemahaman bersama terhadap masalah yang harus dipecahkan, keterampilan, pengalaman, dan kompetensi; agar proses realisasi program dan pengembangannya dapat tercapai dengan optimal. Kaji tindak partisipatif merupakan kombinasi antara penelitian (research) dengan tindakan (action) yang dilakukan secara partisipatif guna meningkatkan aspek kehidupan masyarakat.

Metode kedua, adalah dengan metode peer coaching, yaitu suatu metode yang dilakukan untuk menyampaikan informasi, pesan, ide, pengetahuan yang dilakukan oleh teman sejawatnya. Dalam hal ini kami dosen Universitas Serang Raya merupakan 
teman sejawat bagi para pelaku UMKM. Tentunya ini didasari dengan pertimbangan agar kami dapat memperoleh informasi yang seluas-luasnya tentang proses bisnis dan permasalahan yang ada di UMKM. Sedangkan teknik penyampaian sosialisai pentingnya CRM bagi UMKM adalah: ceramah, tanya jawab, diskusi, dan kuisioner.

\section{Tahapan Program Kegiatan}

Langkah-langkah yang dilakukan dalam kegiatan pengabdian masyarakat ini sebagai solusi permasalahan yang terjadi pada UMKM di wilayah Cilegon adalah:

a. Melakukan studi pendahuluan berupa kajian literatur terkait dan studi lapangan awal terkait UMKM di wilayah Cilegon.

b. Melakukan survey dan observasi terhadap para pelaku UMKM di wilayah Cilegon terkait pemanfaatan CRM dan TIK.

c. Melakukan sosialisasi pentingnya pemanfaatan Customer Relationship Management (CRM) dalam upaya meningkatkan retensi pelanggan pada Usaha Mikro Kecil Dan Menengah (UMKM) di Cilegon.

\section{HASIL KEGIATAN}

Sosialisasi pentingnya pemanfaatan Customer Relationship Management (CRM) dalam upaya meningkatkan retensi pelanggan pada Usaha Mikro Kecil Dan Menengah (UMKM) telah dilakukan terhadap 10 (sepuluh) pelaku UMKM Cilegon yang tergabung dalam HIPMIKINDO Wilayah Cilegon.

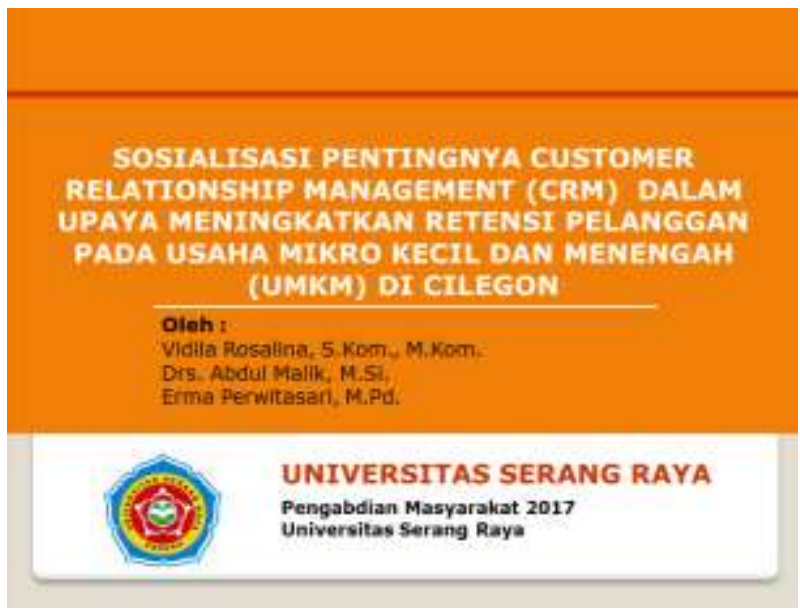

\section{Gambar1. Presentasi Sosialisasi}

Dari pertanyaan pre test yang bersifat menggali kepada 30 pelaku UMKM tersebut, sebanyak 100\% belum pernah memanfaatkan CRM dan belum memahami pentingnya pemanfaatan CRM upaya meningkatkan retensi pelanggan UMKM (lihat Tabel 1).
Dari hasil post test yang dilakukan setelah sosialisasi pentingnya pemanfaatan Customer Relationship Management (CRM) dalam upaya meningkatkan retensi pelanggan pada Usaha Mikro Kecil Dan Menengah (UMKM), didapatkan hasil bahwa $90 \%$ pelakU UMKM di Cilegon memahami pentingnya CRM dan siap untuk memanfaatkan CRM dalam meningkatkan retensi pelanggannya.

\section{Tabel 4. Data Responden Pemahaman Pentingnya} CRM

\begin{tabular}{clc}
\hline No & Tingkat Pemanfaatan & Smartphone \\
\hline \hline 1 & Tidak Memahami & 0 \\
\hline 2 & Sedikit Memahami & 1 \\
\hline 3 & Lumayan Memahami & 2 \\
\hline 4 & Memahami & 27 \\
\hline \hline
\end{tabular}

Tabel 5. Data Responden Kesiapan Pemanfaatan CRM

\begin{tabular}{llc}
\hline No & Tingkat Pemanfaatan & Smartphone \\
\hline \hline 1 & Tidak Siap & 0 \\
\hline 2 & Belum Siap & 1 \\
\hline 3 & Siap & 2 \\
\hline 4 & Sangat Siap & 27 \\
\hline \hline
\end{tabular}

\section{KESIMPULAN}

a. Meningkatnya pemahaman para pelakU UMKM tentang pentingnya pemanfaatan CRM dalam upaya meningkatkan retensi pelanggan UMKM sebesar $90 \%$.

b. Tingkat kesiapan para pelaku UMKM di wilayah Cilegon dalam menerima penerapan CRM adalah sangat siap (90\%).

c. Para pelaku UMKM hampir $100 \%$ pengguna smartphone sehingga pengembangan sistem CRM ke depan sebaiknya berbasis Android.

\section{PUSTAKA}

Danardatu, Aloysius Heru. 2003, Pengenalan Customer Relationship Management, IImu Komputer.com.

Rifa'i, B. (2013). Efektivitas Pemberdayaan Usaha Mikro Kecil dan Menengah (UMKM) Krupuk Ikan dalam Program Pengembangan Labsite Pemberdayaan Masyarakat Desa Kedung Rejo Kecamatan Jabon Kabupaten Sidoarjo. Kebijakan dan Manajemen Publik, 130-136.

Rosalina, Vidila., dkk. 2017. Electronic Customer Relationship Management (E-CRM) Modeling on Micro, Small \& Medium Enterprises (MSMEs) Banten, IJCA October 2017 Edition.

Sawitri,P., Wulandari, L., Simri, L.I.W. 2012. CRM untuk UKM, Konferensi Nasional Sistem Informasi 2012, STMIK STIKOM Bali 23-25 Pebruari 2012. 